\title{
Is the Eggshell Quality Influenced by the Egg Weight or the Breeder Age?
}

http://dx.doi.org/10.1590/1806-9061-2018-0896

\section{-Author(s)}

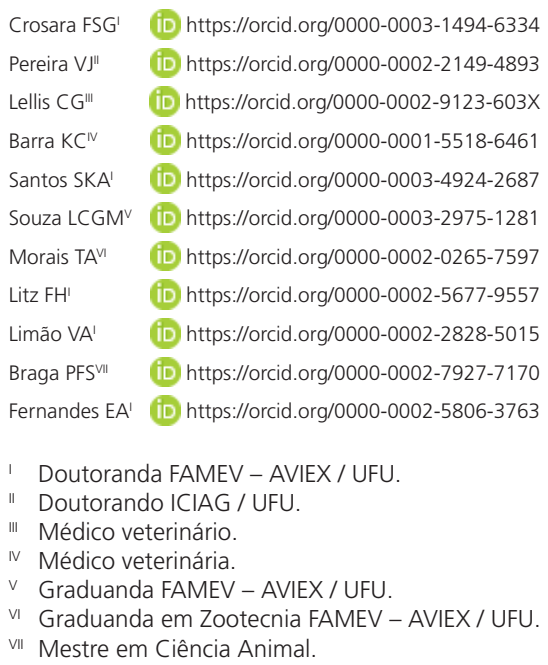

\section{Mail Address}

Corresponding author e-mail address Flávia de Sousa Gomes Crosara

Avenida Segismundo Pereira, 799. Santa Mônica, Uberlândia-MG, Brasil.

Phone: (55 34) 999790568

Email: flaviasgvet@gmail.com

\section{- Keywords}

Broiler breeders. Eggshell thickness. Shell area. Shell index.

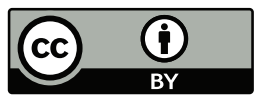

Submitted: 12/September/2018 Approved: 07/December/2018

\section{ABSTRACT}

For a long time, it has been said that eggshell quality decreases as eggs increase in size, but this increase is seen as the breeder age advances. Therefore, the present study aimed to evaluate the age and egg weight effect on Cobb 500 broiler breeders on eggshell quality. The quality measures tested were eggshell and mineral matter percentage, eggshell surface, shape and eggshell index, eggshell and membrane thickness and specific gravity. Eggs from 27, 31, 36, 40, $46,48,53,58$ and 63 week-old breeders were classified as eggs with a constant weight ranging from $63.8 \pm 0.2$; and eggs with increasing weight, according to age, being: $55.8 \mathrm{~g} ; 60 \mathrm{~g} ; 62.2 \mathrm{~g} ; 64.2 \mathrm{~g} ; 65.2 \mathrm{~g}$, $66.6 \mathrm{~g}, 68.1 \mathrm{~g}, 69.9 \mathrm{~g}$ and $72.5 \mathrm{~g}$, respectively. The eggs weight did not influence the eggshell percentage and the specific gravity in seven of the nine tested ages, while for mineral matter in six of the nine studied ages. The shape and shell index, shell and membrane thickness are characteristics independent of egg weight. As the Cobb 500 broiler breeder age advanced, the mineral matter concentration and specific gravity maintained constant, the membrane thickness (R2>70) reduced, and other studied variables were influenced in the same way for both treatments. Thus, the eggshell quality decrease with the advancing age cannot be attributed solely to the increase of egg weight with consequent increase in the eggshell volume and the surface, but there are also age-related factors.

\section{INTRODUCTION}

The egg shell is a complex structure and represents the mineral reserve for embryo use (Solomon, 2010) as well as the physical protection for its growth (Ulmer-Franco et al., 2010). Thus, good quality eggshells must occur throughout all the reproductive life of breeders since they influence the embryonic development (Tůmová \& Gous, 2012). The eggshell quality can be affected by genotype, breeder age, room temperature (Tưmová et al., 2014) and nutrition (Londero et al., 2015; Tůmová \& Gous, 2012), on the other hand, the laying time does not influence the eggshell quality (Gumulka et al., 2010; Tůmová et al., 2014).

The breeder age increasing results in egg production decrease and egg weight increase, which can be attributed to a decrease in the posture sequence (Rutz et al., 2005) and to the increase in the breeder's weight (Tůmová \& Gous, 2012). The eggshell quality deteriorates with the advancing of age (Machal \& Simeonovová, 2002), which is presumably related to the increase in egg size and consequent eggshell surface area (Tůmová \& Ledvinka, 2009).

The eggs' weight from a flock of breeders of the same lineage and age shows distribution in the normal curve and can be influenced by 
Crosara FSG, Pereira VJ, Lellis CG, Barra KC, Santos SKA, Souza LCGM, Morais TA, Litz FH, Limão VA, Braga PFS, Fernandes EA
Is the Eggshell Quality Influenced by the Egg Weight or the Breeder Age? feeding time (Londero et al., 2015), room temperature and laying time (Tůmová \& Gous, 2012). Eggs layed at the beginning of the day, up to 7 a.m., are heavier (Zakaria \& Omar, 2013). According to lqbal et al. (2017), the egg weight influences the eggshell percentage and thickness, shape index and specific gravity which reduce with the weight increase.

A long time ago, it was established the concept that the eggshell quality decreases as a consequence of the egg weight increase and the maintenance of the eggshell amount deposited throughout the reproductive life of the breeder. However, there is a lack of research evaluating, together, the effects of the breeders age and egg weight on the eggshell quality. However, it is hypothesized that the decrease in the eggshell quality with the advancing age is due to the breeder "geriatric" matters and not only to the egg weight increase. Therefore, this study aimed to evaluate the geriatric effect in Cobb 500 broiler breeders in eggshell quality.

\section{MATERIAL AND METHODS}

This study was performed with Cobb 500 broiler breeders, which were housed in nine sites at the same breeding farm, of a Brazilian agroindustrial company that produces broiler chickens, reared in an integration system. The flocks were housed with an average 4-week fallowing, according to the company's housing schedule and the studied ages were: $27,31,36,40$, 46, 48, 53, 58 and 63 weeks old. The breeders and eggs management followed the company's routine and regular activities. At the reproduction stage, females between 27 and 46 weeks of age consumed first laying ration $(2850 \mathrm{kcal} \mathrm{kg-1,16.4 \%} \mathrm{CP} \mathrm{and}$ $3.27 \% \mathrm{Ca}$ ) and females between 47 and 63 weeks of age second laying ration (2800 kcal kg-1, 15.5\% $\mathrm{CP}$ and $3.45 \% \mathrm{Ca}$ ), being the rations produced in the same feed mill and using the same raw materials (Table 1). The daily egg production was sent to the hatchery in the late afternoon and stored under a temperature of $19^{\circ} \mathrm{C}$ and humidity $70 \%$.

The experiment started in the hatchery where 600 hatching eggs from each flock, from the second and third laying collection, were individually weighed in an accuracy scale of 0.01 $\mathrm{g}$, to determine the mean weight (Ewt) for each studied age. From these eggs, two treatments were defined: T1) eggs with constant weight: $63.8 \pm 0.2 \mathrm{~g}$, being this weight determined to occur at all ages and the lowest weight found at 63 weeks; and T2) eggs with increasing weight according to the breeders' age: being these the average weight found for each age with variation of $\pm 0,2 \mathrm{~g}: 55,8 \mathrm{~g} ; 60 \mathrm{~g} ; 62.2 \mathrm{~g} ; 64.2 \mathrm{~g} ; 65.2 \mathrm{~g}, 66.6$ $\mathrm{g}, 68.1 \mathrm{~g}, 69.9 \mathrm{~g}$ and $72.5 \mathrm{~g}$. For each treatment, 15 eggs were separated within each age (135), totalizing 270 eggs. The experiment consisted of a factorial design in subdivided plot, with nine ages in the plot and two categories of egg weight in the subplot.

The eggs specific gravity of each experimental unit was determined by the method of immersion in saline solutions at concentrations of $1.065 ; 1.070 ; 1,075$ and 1,080 (Hamilton, 1982). The eggs remaining at the bottom of the solution of 1.080 were considered as density 1.085 .

The width and height of each egg were measured (Breadth-B; Length-L) with a digital caliper with an accuracy of $0.0001 \mathrm{~mm}$. From the weight and these measurements, the following parameters were calculated:

\section{Shape Index (Carter, 1968): (B / L) x 100}

Egg volume (Ayupov, 1976): Evol $\left(\mathrm{cm}^{3}\right)=0.523 \times L$ $x B^{2}$

Shell (Surface) area (Mueller \& Scott, 1940): SA $\left(\mathrm{cm}^{2}\right)=4.67$ (Ewt) $2 / 3$

The eggshell was washed in running water for the removal of the adhered albumen and dried at room temperature. The eggshell absolute weight (Shell wt) was obtained in a $0.001 \mathrm{~g}$ precision scale. From these measurements, the following parameters were calculated:

$$
\text { Shell }(\%)=(\text { Shell wt / Ewt) } \times 100
$$

Shell index (Sauveur, 1988): SI $\left(\mathrm{g} / \mathrm{cm}^{2}\right)=($ Shell wt I Shell surface area) $\times 100$

Table 1 - Average feed intake (g), energy intake (kcal), crude protein (CP) and calcium (Ca) of Cobb 500 broiler breeders.

\begin{tabular}{cccccccccccc}
\hline & Age & 27 & 31 & 36 & 40 & 46 & 48 & 53 & 58 & 63 \\
\hline \multirow{5}{*}{ Feedintake / day } & $\mathrm{g} / \mathrm{hen}$ & 165 & 165 & 163 & 160 & 157 & 152 & 150 & 148 & 146 \\
& $\mathrm{kcal}$ & 470 & 470 & 465 & 456 & 447 & 433 & 420 & 414 & 409 \\
& $\mathrm{CP}$ & 27.1 & 27.1 & 26.7 & 26.2 & 25.7 & 24.9 & 23.3 & 22.9 & 22.6 \\
& $\mathrm{Ca}$ & 5.4 & 5.4 & 5.3 & 5.2 & 5.1 & 5.0 & 5.2 & 5.1 & 5.0 \\
\hline
\end{tabular}


Crosara FSG, Pereira VJ, Lellis CG, Barra KC, Santos SKA, Souza LCGM, Morais TA, Litz FH, Limão VA, Braga PFS, Fernandes EA

\section{Is the Eggshell Quality Influenced by the Egg Weight or the Breeder Age?}

The eggshell with membrane thickness (EWMT) was obtained by a "conical tip" micrometer with an accuracy of $0.001 \mathrm{~mm}$ and performed in three regions of the meridian. Then, the eggshells were submerged in $10 \%$ sodium hydroxide solution $(\mathrm{NaOH})$ for 10 minutes, washed in distilled water and dried at room temperature to measure the eggshell without membrane thickness (EWOMT). The eggshell membrane thickness was obtained by the difference:

Eggshell membranes thickness EMT $=(E W M T-$ EWOMT)

Afterwards, the eggshells were ground to determine the mineral matter content (MM) by incinerating the sample in a muffle oven at $500^{\circ} \mathrm{C}$ for 4 hours.

$$
M M \%=(\text { final weight } / \text { initial weight } \times 100)
$$

The obtained data were analyzed for the residue's normality (Kolmogorov-Smirnov test; $p<0.01$ ) and variances homogeneity (Levene test; $p<0.01$ ). Afterwards, they were submitted to ANOVA ("Snedecor" F test, $p<0.05$ ). The comparison between the egg types was performed by the Tukey test $(p<0.05)$ and regression models were used to monitor the effect of breeders' age on eggs ( $\left.p<0.05 ; R^{2} \geq 70 \%\right)$.

\section{RESULTS}

The constant (T1) and increasing (T2) egg weight and the eggshells variables are presented in table 2 . The eggshell percentage was not dependent of egg weight, exception at 27 and 63 weeks of age, when eggs with higher weight presented lower eggshell percentage.

Table 2 - Percentage of eggshell, shell weight, mineral matter, specific gravity, shape index, egg volume, eggshell area and shell index of constant (T1) and increasing (T2) weight eggs from Cobb 500 broiler breeders.

\begin{tabular}{|c|c|c|c|c|c|c|c|c|c|c|}
\hline \multirow[b]{2}{*}{ Age } & \multicolumn{2}{|c|}{ Shell Percentage } & \multicolumn{2}{|c|}{ Mineral Matter (\%) } & \multicolumn{2}{|c|}{$\begin{array}{l}\text { Specific gravity } \\
\left(\mathrm{g} \mathrm{mL}^{-1} \text { of } \mathrm{H}_{2} \mathrm{O}\right)\end{array}$} & \multicolumn{2}{|c|}{ Egg volume $\left(\mathrm{cm}^{3}\right)$} & \multicolumn{2}{|c|}{ Shell area $\left(\mathrm{cm}^{2}\right)$} \\
\hline & $\mathrm{T} 1$ & $\mathrm{~T} 2$ & $\mathrm{~T} 1$ & $\mathrm{~T} 2$ & $\mathrm{~T} 1$ & $\mathrm{~T} 2$ & $\mathrm{~T} 1$ & $\mathrm{~T} 2$ & $\mathrm{~T} 1$ & $\mathrm{~T} 2$ \\
\hline 27 & $9.85 b$ & $10.53 a$ & $96.88 a$ & $96.78 a$ & $1084 a$ & $1085 a$ & $58.46 a$ & $51.77 \mathrm{~b}$ & $74.59 a$ & $68.31 b$ \\
\hline 31 & $10.22 a$ & $10.35 a$ & $96.74 b$ & $97.50 \mathrm{a}$ & $1077 a$ & $1077 a$ & $59.34 a$ & $56.48 b$ & $74.61 a$ & $71.66 b$ \\
\hline 36 & $10.22 a$ & $10.42 a$ & $95.87 b$ & $97.11 a$ & $1076 a$ & $1075 a$ & $59.17 a$ & $57.71 b$ & $74.59 a$ & $73.44 b$ \\
\hline 40 & $9.77 a$ & $9.99 a$ & $97.28 a$ & $97.27 a$ & $1074 a$ & $1074 a$ & $59.67 a$ & $58.89 \mathrm{~b}$ & $74.63 b$ & $74.95 a$ \\
\hline 46 & $10.43 a$ & $10.32 a$ & $97.33 a$ & $95.77 b$ & $1075 a$ & $1074 a$ & $59.57 b$ & $60.73 a$ & $74.75 b$ & $75.80 a$ \\
\hline 48 & $9.95 a$ & $10.32 a$ & $97.15 a$ & $96.81 \mathrm{a}$ & $1074 b$ & $1076 a$ & $59.10 b$ & $62.10 a$ & $74.64 b$ & $76.87 a$ \\
\hline 53 & $10.46 a$ & $10.36 a$ & $97.29 a$ & $96.62 a$ & $1075 a$ & $1076 a$ & $59.11 b$ & $62.93 a$ & $74.65 b$ & $78.02 a$ \\
\hline 58 & $10.66 a$ & $10.72 a$ & $96.77 a$ & $96.94 a$ & $1075 a$ & $1076 a$ & $58.86 b$ & $64.46 a$ & $74.63 b$ & $79.33 a$ \\
\hline 63 & $10.52 a$ & $9.50 \mathrm{~b}$ & $96.92 a$ & $97.44 a$ & $1077 a$ & $1074 b$ & $59.20 \mathrm{~b}$ & $67.46 a$ & $74.64 b$ & $81.32 a$ \\
\hline Média & 10.23 & 10.28 & 96.91 & 96.92 & 1076 & 1076 & 59.16 & 60.00 & 74.64 & 75.52 \\
\hline$C V(T \times A)$ & \multicolumn{2}{|c|}{$6.44 \%$} & \multicolumn{2}{|c|}{$0.55 \%$} & \multicolumn{2}{|c|}{$0.17 \%$} & \multicolumn{2}{|c|}{$1.41 \%$} & \multicolumn{2}{|c|}{$0.19 \%$} \\
\hline F K-S & 0.994 & 0.054 & 2.266 & 0.123 & 4.43 & 0.418 & 1.775 & 0.09 & 2.424 & 0.055 \\
\hline \multirow[t]{2}{*}{$p(T \times A)$} & \multicolumn{2}{|c|}{0.0005} & \multicolumn{2}{|c|}{0.0001} & \multicolumn{2}{|c|}{0.0000} & \multicolumn{2}{|c|}{0.000} & \multicolumn{2}{|c|}{0.0000} \\
\hline & \multicolumn{2}{|c|}{ Shape Index (\%) } & \multicolumn{2}{|c|}{ Shell index $\left(\mathrm{g} / 100 \mathrm{~cm}^{2}\right)$} & \multicolumn{2}{|c|}{ EWMT (mm) } & \multicolumn{2}{|c|}{ EWOMT (mm) } & \multicolumn{2}{|c|}{$\mathrm{EMT}(\mathrm{mm})$} \\
\hline Age & T1 & $\mathrm{T} 2$ & $\mathrm{~T} 1$ & $\mathrm{~T} 2$ & $\mathrm{~T} 1$ & $\mathrm{~T} 2$ & $\mathrm{~T} 1$ & $\mathrm{~T} 2$ & $\mathrm{~T} 1$ & $\mathrm{~T} 2$ \\
\hline 27 & 75.71 & 74.96 & 8.42 & 8.65 & 0.318 & 0.318 & $0.240 a$ & $0.243 a$ & 0.077 & 0.077 \\
\hline 31 & 76.46 & 76.09 & 8.73 & 8.68 & 0.294 & 0.308 & $0.237 a$ & $0.232 a$ & 0.063 & 0.068 \\
\hline 36 & 77.28 & 77.55 & 8.73 & 8.84 & 0.278 & 0.283 & $0.228 a$ & $0.224 a$ & 0.051 & 0.064 \\
\hline 40 & 77.03 & 76.56 & 8.34 & 8.55 & 0.278 & 0.276 & $0.226 a$ & $0.224 a$ & 0.051 & 0.055 \\
\hline 46 & 77.21 & 77.14 & 8.87 & 8.92 & 0.287 & 0.298 & $0.251 a$ & $0.251 a$ & 0.048 & 0.047 \\
\hline 48 & 77.50 & 76.87 & 8.5 & 8.93 & 0.280 & 0.289 & $0.241 b$ & $0.248 a$ & 0.039 & 0.041 \\
\hline 53 & 76.02 & 76.11 & 8.93 & 9.03 & 0.285 & 0.292 & $0.252 b$ & $0.266 a$ & 0.035 & 0.032 \\
\hline 58 & 77.18 & 76.65 & 9.1 & 9.41 & 0.308 & 0.317 & $0.248 b$ & $0.272 a$ & 0.037 & 0.043 \\
\hline 63 & 75.01 & 75.76 & 8.99 & 8.43 & 0.302 & 0.283 & $0.257 a$ & $0.243 b$ & 0.041 & 0.037 \\
\hline Média & $76.61 a$ & $76.43 a$ & $8.74 a$ & $8.82 a$ & $0.292 a$ & $0.296 a$ & 0.242 & 0.245 & $0.050 a$ & $0.052 a$ \\
\hline$C V(T \times A)$ & \multicolumn{2}{|c|}{$4.20 \%$} & \multicolumn{2}{|c|}{$6.45 \%$} & \multicolumn{2}{|c|}{$8.02 \%$} & \multicolumn{2}{|c|}{$3.64 \%$} & \multicolumn{2}{|c|}{$28.75 \%$} \\
\hline F K-S & 1.508 & 0.055 & 1.032 & 0.053 & 1.254 & 0.034 & 2.738 & 0.038 & 1.471 & 0.04 \\
\hline$p(T \times A)$ & \multicolumn{2}{|c|}{0.9947} & \multicolumn{2}{|c|}{0.0603} & & & & & & \\
\hline
\end{tabular}

${ }^{1}$ Averages followed by different letters in the line into each variable, differ between them by Tukey test at 0.05 of significance; ${ }^{2} \mathrm{C} . \mathrm{V}$.: Experimental variation coefficient; ${ }^{3}{ }^{\prime} ;{ }^{2} \mathrm{~K}-\mathrm{S}$ : Levene and Kolmogorov-Smirnof test statistic; values in black indicate homogeneous variance and residues with regular distribution, respectively, both at 0.01 of significance; $3 \mathrm{P}$ ( $\mathrm{T} \times \mathrm{A})$ : probability of the statistic of Snedecor test. 
Crosara FSG, Pereira VJ, Lellis CG, Barra KC, Santos SKA, Souza LCGM, Morais TA, Litz FH, Limão VA, Braga PFS, Fernandes EA Is the Eggshell Quality Influenced by the Egg Weight
or the Breeder Age?
In general, the eggs had the same specific gravity, independent of egg weight, except those from 48 and 63-week-old breeders, where increasing and constant weight eggs resulted in higher specific gravity, respectively (1.076 and 1.077). The mineral matter percentage in the eggshells did not vary with the eggs weight, except with 31, 36 and 46-week-old breeders, whose eggs of greater weight presented lower mineral matter percentage. Mineral matter and specific gravity were stable, with little variation among the repetitions, according to age and egg weight, confirmed by the low coefficients of sensu Pimentel-Gomes (2000).

Egg volume and eggshell surface were directly related to egg weight, while egg shape index $(p=0.9947)$ and eggshell ( $p=0.0603$ ) were not dependent, being the averages variation close to $76.5 \%$ and $8.78 \mathrm{~g}, 100 \mathrm{~cm}^{-2}$, respectively.

The eggshell with membrane and membrane thickness did not follow the eggs weight among the treatments. For shell without membrane thickness there was a difference among treatments over 48 weeks of age, and from 48 to 58 weeks of age, the lower weight (T1) eggs had lower thickness, and at 63 weeks of age, there was an inversion of this behavior.

Characteristics of eggshell quality and breeders' age are in Figure 1. The percentages of eggshell weight of both treatments over time were dispersed, not fitting to the models tested (Figure 1A), while the percentage of mineral matter of the shells remained constant (between 95.87 and 97.5\%) with the advancement of time (Figure 1B).

For specific gravity, an extreme point in constant and increasing eggs from 27-week of age birds was seen and, therefore, the decreasing exponential model was adjusted. From 31 weeks of age on (Figure 1C), the curves were similar, remaining practically constant up to 63 weeks ( $R^{2}=94.04 \%$ and $95.06 \%$ respectively).

The breeder age advancement had low impact on the egg shape index (Figure 1D), not adjusting to the regression models tested by the unpredictability of response. However, for both treatments, low rates can be observed in early ages followed by an increase up to around 46 weeks and decreasing values from that age, however this variable presents low variation throughout the bird life (75 to $77.5 \%$ ).

Egg volume (Figure 1E) and shell surface (Figure $1 \mathrm{~F})$ at T2 presented weekly linear increases of 0.3751 $\mathrm{cm}^{-3}$ and $0.3219 \mathrm{~cm}^{-2}$, respectively, with the age advancement ( $R^{2}$ above $95 \%$ ). These variables show values almost constant for T1, confirming the direct relation of these characteristics with the egg weight without, however, being influenced by the age, and did not fit to any regression curve. The amount of shell deposited per area (Figure 1G) did not fit to the regression models, and when analyzing the dispersion, it is noted that most of the data present a linear increasing trend with age in both treatments suggesting an increase of shell deposition due to the age increase. Scattered spots were observed at 40, 48 and 63 weeks of age.

The eggshell with membrane thickness (Figure $1 \mathrm{H})$ showed an adjustment to the quadratic model for eggs with constant weight $\left(R^{2}=77.7 \%\right)$, minimum point close to 44 weeks of age, reaching a minimum thickness of $0.280 \mathrm{~mm}$. The eggshell thickness for increasing weight eggs, although not adjusting to any regression model $\left(R^{2} \geq 70 \%\right)$, the data tended to quadratic, with scattered points at 48 and 63 weeks of age. The eggshell without membrane thickness (Figure 1I) decreased until the $40^{\text {th }}$ week old and from the $46^{\text {th }}$ week on, both treatments increased. The eggshell membrane thickness of constant (T1) and increasing (T2; Figure 1J) weight eggs decreases 0.0010 and $0.0012 \mathrm{~mm}$ with increasing age, $R^{2}=79.5 \%$ and $\mathrm{R}^{2}=87 \%$, respectively.

\section{DISCUSSION}

The egg volume and the eggshell surface area had the same behavior of egg weight for both treatments, that is, constant for treatment 1 and increasing for treatment 2. For Tumova \& Ledvinka (2009), the eggshell quality decrease, with the advancing age, is related to the egg size and eggshell surface area increase. However, in this study, the same behavior among treatments was observed for eggshell quality.

The percentage deposition of mineral matter in the eggshell throughout the breeder life was practically constant for both treatments, indicating that the contents available to the eggshell are the same throughout the breeder life regardless of the egg weight. Although the eggshell index and percentage had shown an increasing linear trend with increasing age, the mineral matter percentage remained constant. This way, the transfer of minerals from the bird to the egg throughout the life does not compete for impairment in the eggshell quality.

The specific gravity behavior related to egg weight demonstrates that this variable is constant, which corroborates with Frank et al. (1964) who found a low correlation ( $R=0.14)$ among these variables. The specific gravity along with the advancing age showed a drop from 27 to 31 weeks of age, possibly due to 
Crosara FSG, Pereira VJ, Lellis CG, Barra KC, Santos SKA, Souza LCGM, Morais TA, Litz FH, Limão VA, Braga PFS,

Fernandes EA
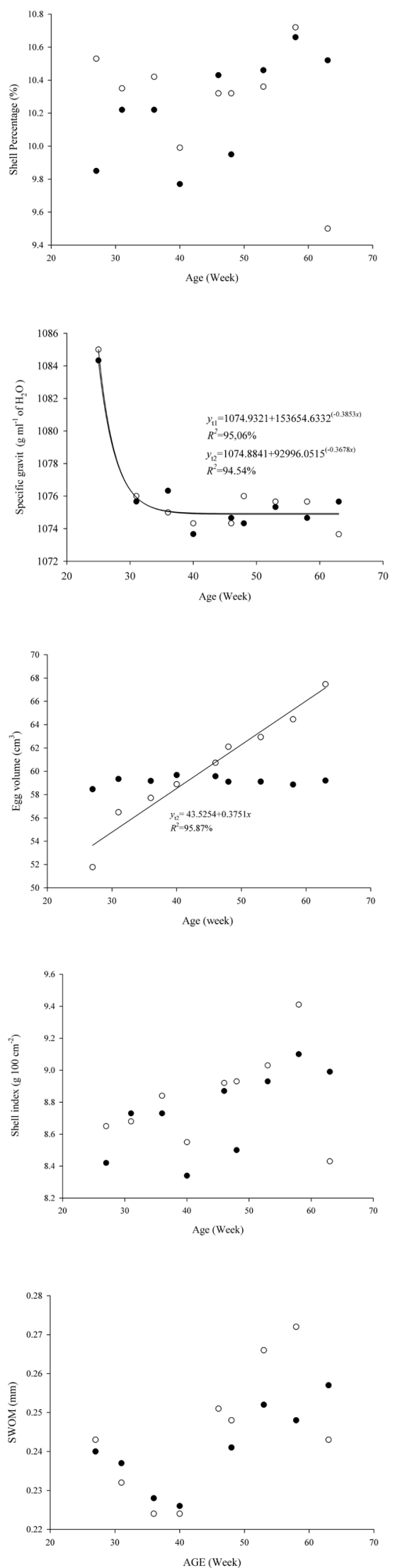

A

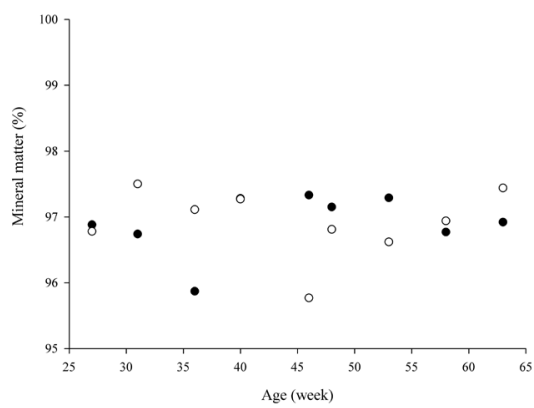

B

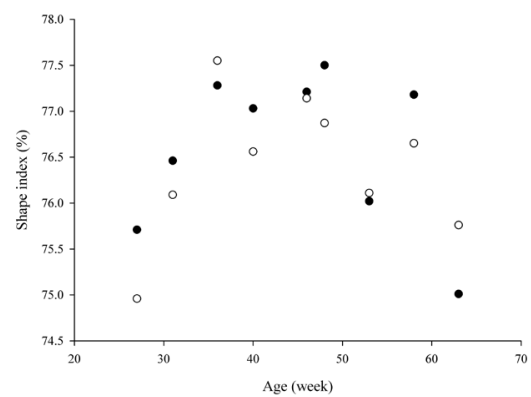

D

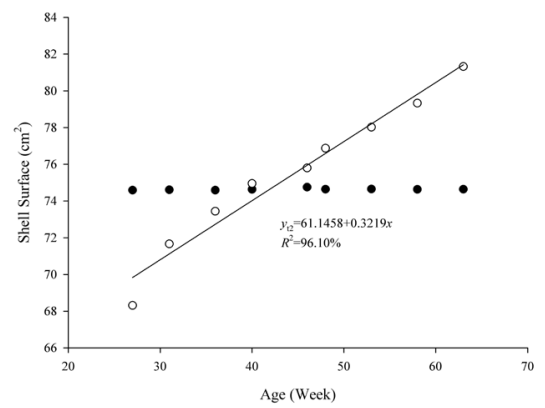

F

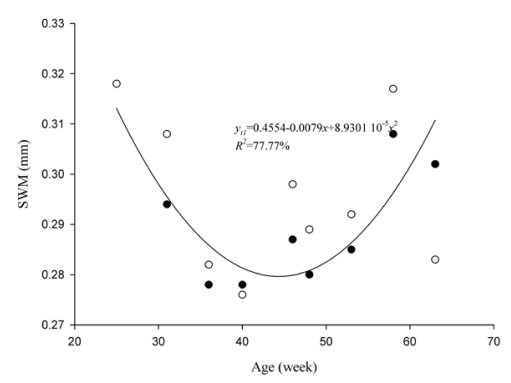

G

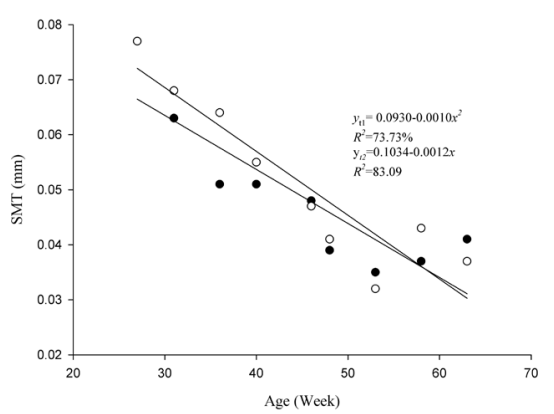

Figure 1 - Description and quality of constant (T1•) and increasing (T20) eggshell mass from Cobb 500 broiler breeders. Eggshell percentage (A), Mineral matter (B), Specific gravity (C), Shape index (D), Egg volume (E), Eggshell area (F) and eggshell index (G), EWM - Egghell thickness with membrane (H), EWOM - Eggshell thickness without membrane (I) e EMT - Eggshell membrane thickness (J). 
Crosara FSG, Pereira VJ, Lellis CG, Barra KC, Santos SKA, Souza LCGM, Morais TA, Litz FH, Limão VA, Braga PFS, Fernandes EA Is the Eggshell Quality Influenced by the Egg Weight
or the Breeder Age? the beginning of the birds' egg production, but from 31 to 63 weeks of age, it remained constant, which could be attributed to the genetic evolution of the studied lineage. Similar behavior, with reduction at the beginning of the posture and maintenance in the next phase was observed in the same lineage (Kontecka et al., 2012). For Tumova \& Gous (2012) the interaction of four factors (bird type, age, oviposition and temperature) affects more intensely the specific gravity, than a single factor. As the eggs of this experiment came from the same lineage, same laying date, temperature and collection time, we can infer that the factors that influenced the specific gravity were minimized, confirming to be a constant variable independent of the breeder age gain or of the egg increasing weight.

The eggshell thickness is not influenced by the egg weight, which corroborates with Wolanski's et al. (2007) findings, of low correlation $(R=0.02)$. Regarding age, the thickness decreases up to 48 weeks of age and presents increasing values from this age on. This result can be related to the breeders feeding management with feed amount weekly reducted, with the same nutritional levels from the beginning of the laying until 46 weeks old, concomitant with laying high index and persistence. However, following the company's nutritional program, after 48 weeks of age another nutritional formulation is provided, with an increase in the daily calcium supply, coinciding with the period that the breeder is reducing the laying index (Table 1).

The eggshell membrane thickness decreases with the breeder increasing age. The membrane thickness decrease would be related to the physical barrier quality decrease (Mine, 2003), in addition, this reduction can affect the eggshell structure (Barbosa et al., 2012).

In general, hatching eggs are oval shaped according to the shape index (SI of 74.96 to $77.55 \%$ ) which is independent of the weight, probably the genetic selection of the lineage sought to maximize the use of eggs for incubation. According to Sarica \& Erensayin (2009), round and long eggs do not fit well on the cartons, being more prone to cracking and breaking during transport and handling. The egg shape index throughout the breeder life, although presenting close values, showed a quadratic tendency, that is, until half of the breeder life, the eggs tend to be subtly rounded and from that phase on, elongated. Similar results to the one reported by Tumova \& Gous (2012) in a research with the same lineage (Cobb), with eggs from 36 and 64-week-old breeders, found a change in the shape index, with the birds' age increase, being older breeders the ones that produce longer eggs.

\section{CONCLUSION}

Cobb 500 broiler breeders increasing age affects the eggshell quality, independent of the egg's weight, maintaining the mineral matter concentration constant. Thus, the eggshell quality decrease with the advancing age cannot be attributed solely to the egg weight, volume and shell surface increase, but also to geriatric factors.

\section{REFERENCES}

Ayupov FG. On the egg mathematical model. Advanced Scientific-Industrial Experience in Poultry Breeding. Express information 1976;9:14-6.

Barbosa VM, Baião NC, Mendes PMM, Rocha JSR, Pompeu MA, Lara LJC, Martins NRS, Nelson DL, Miranda DJA, Cunha CE, Cardoso DM, Cardeal PC. Avaliação da qualidade da casca dos ovos provenientes de matrizes pesadas com diferentes idades. Arquivo Brasileiro de Medicina Veterinária e Zootecnia 2012;64(4):1036-44.

Carter TC. The hen's egg. A mathematical model with three parameters. British Poultry Science 1968; 9: 165-71.

Frank FR, Swanson MH, Burger RE. The Relationships Between Selected Physical Characteristics and the Resistance to Shell Failure of Gallus Domesticus Eggs. Poultry Science 1964; 43(5):1228-35.

Gumulka M, Kapkowska E, Maj D. Laying pattern parameters in broiler breeder hens and intrasequence changes in egg composition. Czech Journal of Animal Science 2010;55 (10): 428-35.

Hamilton RMG. Methods and factors that affect the measurement of shell quality. Poultry Science 1982;61(6):2022-39.

Iqbal J, Mukhtar N, Rehman ZU, Khan SH, Ahmad T, Anjum MS, Pasha $\mathrm{RH}$, Umar S. Effects of egg weight on the egg quality, chick quality, and broiler performance at the later stages of production (week 60) in broiler breeders. The Journal of Applied Poultry Research 2017;26( 2): 183-91.

Kontecka H, Nowaczewski S, Sierszula M M, Witkiewicz K. Analysis of changes in egg quality of broiler breeders during the first reproduction period. Annals of Animal Science 2012;12(4) 611-22.

Londero A, Rosa AP, Giacomini CBS, Vivas CEB, Orso C, Freitas HM, Gressler $L$, Vargas $A C$. Effect of different feeding schedules on reproductive parameters and egg quality of broiler breeders. Animal Feed Science and Technology 2015; 210:165-71

Machal L,Simeonovová J. The relationship of shortening and strength of eggshell to some egg quality indicators and egg production in hens of different initial laying lines. Archiv fur Tiezucht 2002;45(3):287-96.

Mine Y, Oberle C, Kassaify Z. Eggshell Matrix Proteins as Defense Mechanism of Avian Eggs. Journal Agricultural and Food Chemistry 2003;51(1):249-53.

Mueller CD, Scott HM . The porosity of the eggshell in relation to hatchability. Poultry Science 1940;19 (3):163-66.

Pimentel-Gomes F. Curso de estatística experimental. 14ed. Piracicaba: Degaspari; 2000.

Rutz F, Anciutti MA, Pan EA. Fisiologia e Manejo reprodutivo das aves. In: Macari M, Mendes AA. editor. Manejo de matrizes de corte. Campinas: Fundação APINCO de Ciência e Tecnologia Avícolas; 2005. p. 75-122. 
Crosara FSG, Pereira VJ, Lellis CG, Barra KC, Santos SKA, Souza LCGM, Morais TA, Litz FH, Limão VA, Braga PFS, Fernandes EA

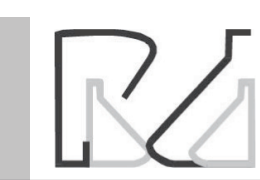

Is the Eggshell Quality Influenced by the Egg Weight or the Breeder Age?
Sarica M, Erensayin C. Poultry Products. In: Turkoglu M, SARICA M, editor. Poultry science. ANKARA: Bey-Ofset; 2009. p. 89-138.

Sauveur B. Reproduction des volailles et production d'oeufs. Paris, FR / Inra Editions; 1988.

Solomon SE. The eggshell: strength, structure and function. British Poultry Science 2010; 51 (1):52-9.

Tumova E, Gous RM. Interaction between oviposition time, age, and environmental temperature and egg quality traits in laying hens and broiler breeders. Czech Journal of Animal Science 2012;57(12):541-49.

Tumova E, Gous RM, Tyler N. Effect of hen age, environmental temperature, and oviposition time on egg shell quality and egg shell and serum mineral contents in laying and broiler breeder hens. Czech Journal of Animal Science 2014;59(9):435-43.
Tumova E, Ledvinka Z. The effect of time of oviposition and age on egg weight, egg components weight and eggshell quality. Archiv fur Geflugelkunde 2009;73(2):110-15.

Ulmer-Franco AM, Fasenko GM, O'Dea Christopher EE. Hatching egg characteristics, chick quality, and broiler performance at two breeder flock ages and from three egg weights. Poultry Science 2010; 89 (12): 2735-42.

Zakaria $\mathrm{AH}$, Omar $\mathrm{OH}$. Egg laying pattern, egg weight, body weight at hatch, and sex ratio bias relative to oviposition time of young-and mid-age broiler breeders. Animal Reproduction Science 2013;141 $1-2): 80-85$. 
